\title{
AdDRESS BY THE PRESIDENT
}

\author{
A. D. JONES, Esq., M.I.Mech.E.,
}

Outdoor Locomotive Superintendent, S.E. and C. Railway.

January $27 t h, 1917$.

Gentlemen,-I thank you for the honour you have conferred on me in asking the to become your President for this year.

At first I felt very diffident about accepting your invilation on account of being so fully occupied-you have, however, some very persistent officers and so I finally gave way. But these are exceptionally busy days for anyone connected with transport, and although I will do my best to fulfil the duties of a President, I must ask for your indulgence, especially towards the short address I am about to give, as I am afraid it will fall far short of the high standard you have been accustomed to in past years.

I propose to put before you a few notes on the "Locomotive Running Department," and if any of my remarks should prompt a member with a subject for a paper for this session, I shall be very pleased.

The English railways have until recent years always made the Outdoor Locomotive or Running Department a section of the Chief Mechanical Engineer's Department, but this practice has been departed from on three of the railways. On one it is under the (ieneral Superintendent, who controls also the operating section of the Traffic Department; on another it is under a Superintendent of Operations (both locomotive and traffic); and in the third instance it is a separate department, including the examination and lubrication of all rolling stock in traffic and cleaning of coaches.

In each case, however, a locomotive engineer is the head of the department.

The repair staffs at the engine sheds in the first and last instances are under the control of the Running Department, and in the second case under the Chief Mechanical Engineer. 


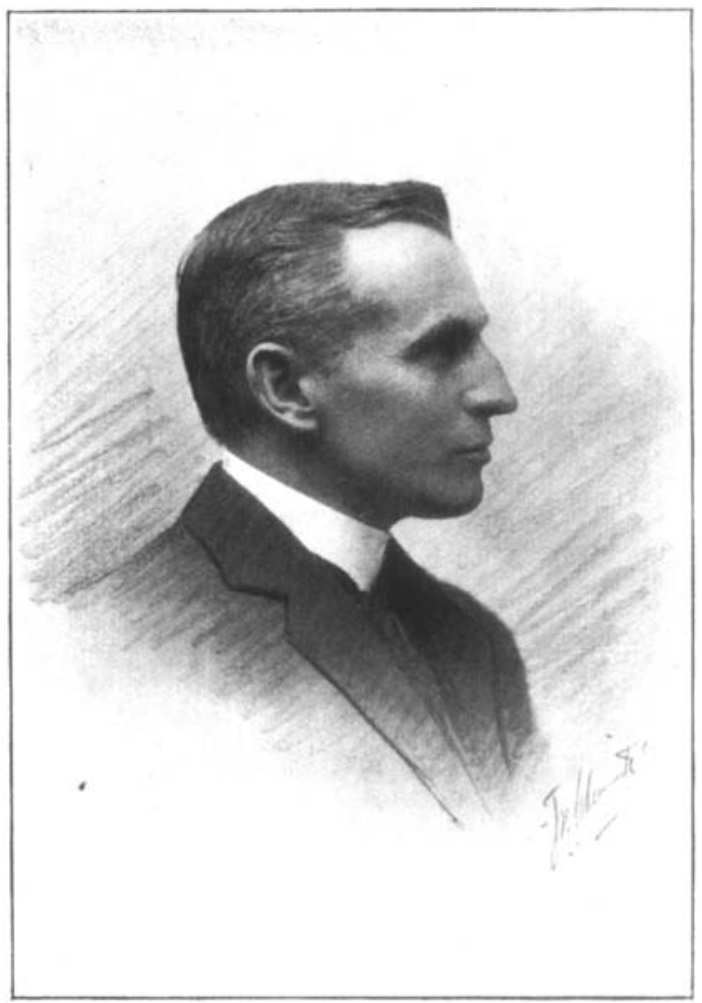

A. D. Jones, M.I.MECh.E.,

President, i9i7. 
It is natural that such a radical departure from the usual practice should be the subject of criticism, but I do not intend to touch on the various arguments raised for or against the change, beyond stating that I consider the Outdoor Locomotive Staff should be under the supervision of a superintendent whe has has been trained from the first as a locomotive engineer.

The headquarter offices should be, if possible, at the same station as the offices of the Traffic Operating Department. The officers of the two departments have so many things in common that frequent opportunities for discussion save much delay and unnecessary correspondence.

The work at headquarters is usually divided into about five sections, such as:-

1. General correspondence and distribution of coal to the various locomotive depots.

2. Reports and investigation of accidents; delays and irregularities.

3. Staff matters.

4. Arrangement of engine workings.

5. Reports and investigation of engine failures and experiments, dealing with stores requisitions and supply.

Railways south of the Thames are under a great disadvantage compared with other companies, owing to the long distance coal has to be brought, not only increasing the price but causing greater uncertainty of arrival, in foggy wather especially. It is advisable to keep considerable stocks in reserve, and it may interest members to know that good hard Yorkshire steam coal can be stacked as long as twenty years and give excellent results when burned.

You have, I believe, had some excellent papers read here on running shed equipment, so I shall not say much on that subject, but there are just one or two points I should like to emphasise. One is the great advanage of a wheel drop in place of a pair of sheerlegs, even if the latter are worked by electric or hydraulic power.

So much more uncoupling has to be done before a lift can be made with sheerlegs. Take as an instance a hot box on the trailing coupled axle of a 4-4-o engine with a tender.

The outside rods have to be taken down and the springs and axlebox keeps on the trailing axle also in both cases, but with sheerlegs the tender has to be disconnected with its many intermediate connections for water, steam 
heating and brakes, as well as taking off the life guards at the leading end. After all this has been done a large proportion of the weight of the engine has to be lifted up instead of lowering about three tons.

Such a ready means for examination of axleboxes and journals makes it possible between trips to attend to boxes which are not running well, instead-at any rate during busy times-of taking the risk of allowing the box to work round at the cost perhaps of a failure on the road and damage to a journal.

Again, wheels can be taken out while the engine is in steam, which cannot be done with a pair of sheerlegs.

A second point I will refer to is the provision at large coaling centres of some type of mechanical coaling plant. There are several kinds at work on English railways giving good results, largely reducing the cost of coaling and enabling an engine to be coaled fully in less than five minutes by one man manipulating a lever.

One of the difficulties to contend with, however, is the emptying of the loaded wagon, owing to the variety of wagon types in use, or rather the position of the doors; some have side doors, others only end doors, and again some have bottom doors only. The ideal system is to have a high level road for loaded coal wagons, so that the contents can be dropped straight into the large distributing bins of the plant.

An important section of the headquarters office is the one dealing with casualties or engine failures. By careful investigation and inspection of the part that has failed much can be learned which will be of use in preventing further casualties, or at any rate reducing the number.

All fiailures should be tabulated under the various headings and returns made to the Chief Mechanical Englneer, so that any weakness in design or manufacture may be gone into in the drawing office or works. The provision of ample pit accommodation for examination purposes at the engine shed prior to starting and again on finishing work, as well as in terminal station sidings, has a decided bearing in the number of failures of the kind that can be prevented by careful inspection, especially on engines with inside cylinders.

In the days when a driver was always kept to one engine he showed far more interest in his work and care of the engine; owing, however, to the reduction in working 
hours of the enginemen, a large proportion of the locomotive stock is double-shifted and there is not so much personal interest shown by the drivers.

General pooling of locomotives is an objectionable system both from the point of the men as well as from a maintenance of economical use of fuel and oil. It can generally be arranged for an engine to have the same two sets of enginemen booked to it. A locomotive is very similar to a horse-they nearly always differ in some slight respect from others in their class-a driver learns the peculiarities of a particular engine or horse and knows how to humour it and so get the best results.

On some railways great care is taken to keep the locomotives clean, and there is a great deal to be said in favour of the practice; in the first place it enables the driver or mechanic to detect fiaws; secondly, the drivers and repair stalf do their work without getting so dirty themselves; and thirdly, it tends to make enginemen take a pride in their work.

Tor much attention is paid sometimes to the exteriorthe boiler and tank plates-at the expense of the motion and springs.

The consumption of stores and material requires careful checking, both by a distriet foreman and by the headquarter staft, to aroid waste. Stores can be divided under three headings:--

(a) Running stores, such as oil, fire irons, cloths, waste and soft packing.

(b) Materials for repairs.

(c) Stationery.

$\Lambda$ rough "issue" book should be kept to enter each issue of stores at the time, and a " stock of stores" book showing receipts and issues which should be balanced up and checked each month.

A stores clerk or inspector is usually attached to the headquarter staff, his duties including visits to the engine shed stores to examine the books and check the stores issued and remaining on hand. An inspection of the scrap heap is frequently a guide in checking waste of material, for instance, brake blocks being changed before they need be.

Samples of oils received should be taken and sent in for analyis.

A regular system of stores-rans, passing to and from the central stores and works and various engine sheds, 
results in articles new and repaired being quickly received, and vice versa articles for repairs or renewals are sent away from the sheds on the return journey.

I will now pass on to another section--the arrangement of the engine workings. A complete working is got out for each booked engine, showing the light running necessitated by the location of the train, and between what points and at what times trains have to be hauled, etc. These are sent out to the various districts and the men and engines arranged accordingly. Special trains are dealt with in a similar manner, unless the notice is too short, in which case the working is wired out to the district concerned.

When a reprint of the time table is made the revision of the engine workings is very complicated, and even one alteration in the timing of a train may result in many engine arrangements being revised, the engines being so intermixed in their workings, especially those on local workings. Care has also to be taken in allowing reasonable margins between trips for necessary engine purposes; terminal facilities and the class of coal in use having considerable bearing on this point.

This section of the department should work in close co-operation with the Traffic Department in the preparation of the time table; this results in less waste of time in providing proper balances to prevent light running, and perhaps the most essential point, namely, the correct sectional timing for the trains. High speeds are much to be desired, but it is not a wise policy to try the impossible as a general rule. Not only is there a great waste of fuel, but generally a late arrival follows.

I renture to think the passenger, especially the business man, prefers a few minutes longer on the journey and a nunctual arrival than being late at his destination. Therefore, when timings are being gone into, reasonable margins should be arranged at the intermediate stations for loading parcels, etc., and again proper allowance made for speed restrictions in force, instead of punishing the boiler unduly.

Soon after war requirements had depleted the station staff, the trains were arriving at their destination very late, so a revised service was got out allowing extra station time required with the smaller staff; this has resulted in punctual arrivals, and passengers can make their appointments with reasonable certainty of being able to keep them.

Railway companies, who have a number of boat services to contend with, have great difficulties to surmount in 
obtaining punctual running. Imagine the return traffic from the Continent in the summer requiring perhaps five or six trains instead of the usual one. The boat may have had a late start from the other side, and so paths have to be found for the trains running out of the usual course. To cope with this kind of thing it is arranged to have in the working time book what are known as "conditional timings," which have been decided upon so as to cause as slight a dislocation to the ordinary traffic as possible. Then when an extra boat train is ready to leave, it is despatched in one of these conditional timings and wired out along the line.

It will, however, be easily understood how difficult it is to avoid delay to ordinary traffic as soon as an extra boat train runs into a congested suburban area.

I have touched upon the importance of correct sectional timings, but there is another side to the question, and that is the correct loading behind the engine drawbar.

On many railways loading by tonnage is the basis used and this is the best method to adopt. With passenger trains this is quite simple, as every vehicle can carry at each end a tare plate giving the weight to the nearest number of tons. A guard or shunter merely has to pass along the train, adding up the tares of the various coaches, to arrive at the correct tonnage.

It is, however, a very much more complicated matter to deal with goods and mineral trains, as in many instances a wagon cannot be weighed after being loaded without delaying its despatch, and so there is not the same degree of accuracy possible. After some experience, however, a very fair estimate can be arrived at for different classes of traffic, the actual weights of which cannot be obtained. The ideal would, of course, be for every wagon on a train to have a "tonnage label" placed in a rack giving the weight of contents plus the tare.

Then comes the question as to what load an engine should be given. I knew of a case where the tonnage rating of each class of engine was got out in a drawing office by calculation only. The results were curious, and in many cases traffic was held up.

Local knowledge is of great importance, the effect of a rising gradient being largely discounted by the fact of its being approached from a falling gradient without a signal Intervening which might cause a check, in which case the driver could not always be sure of a good run at the bank. 
Curres again have much bearing on speeds, more especially with groods trains.

In fact it is the "context" of curves or gradients which is so important a factor in their effect on the running.

The correct method of fixing the loads for all classes of engines, either for passenger or goods traffic, is by actual test runs.

The fewer vehicles used to carry the load the easier it is to haul a train of given tonnage, but with goods trains the driver's chief anxiety is the controlling of the wagons down a gradient.

In descending a long incline a few wagons, fitted with a power brake, placed next to the engine allow a faster speed to be run, owing to the extra brake power at the command of the driver. It is not necessary to have these fitted wagons tightly coupled with screw couplings, the ordinary three-link coupling being quite satisfactory. A guard will not forget to remind his driver of the extra brake power before starting away. I have lively recollections of standing in an open wagon in a loose coupled goods train when stopping tests were being made with a few vacuum braked goods wagons coupled up to the engine.

Very long trains are run on some railways, on one the limit in number of vehicles being $\mathbf{2} 20$. Successful working with goods trains of any great length is dependent on the provision of running loops, i.c., a loop line into which the train can be turned to let a more important one pass, without the necessity of having to "draw up and back inside," which causes delay.

The Running Department is of ten sorely tried by having so many classes or types of engine. As soon as a new type is put on the road the Traffic Department wants nearly every train worked by it. Great advances have been made on some railways in the reduction of types, and as most lines have sufficient engines of the smaller types for dealing with the lighter classes of branch traffic, I think for many years any new types required can be confined to four, namely :--

Heavy passenger express engine.

Heavy goods main line engine.

Heavy.passenger tank engine.

Cood: shunting engine.

As regards signals the Running Department should be consulted when new signals are to be erected or altered positions are proposed for existing ones. Trees, buildings 
and bridges frequently interfere with the good sighting of a signal, and fast running can easily be affected by a poor " sight." In towns, too, street or shop lights have to be taken into consideration in normal times.

To ensure best results it is usual to have a signal sighting committee, composed of inspectors from the Traffic, Signalling and Running Departments, who go over the ground and view the "sights" if necessary from the footplate.

Another part of the work of the Running Department is the duty of clearing the line in cases of accident. Many years ago it used to be said the safest place in the world was a first class carriage in the middle of a passenger train, and in these days of motor buses and taxis in the public streets it is far more likely to be true. But accidents will occur, and the railway with an efficient breakdown equipment will suffer less from dislocation of the traffic than one with old fashioned appliances.

The advent of the steam accident crane reduced the delays enormously in the case of a serious accident by the rapidity of lift and increased radius of action. A steam crane requires fewer men; at least four men are required to lift with a hand crane, with relays for a long lift, as against one steam crane driver. By using a wire rope instead of chains for lifting, a longer lift can be made, which is of great importance for dealing with rolling stock at the bottom of embankments.

The supporting girders for use when lifting at an angle to the direction of the rails should be carried under the platform in position for running out, much time being saved by this.

The breakdown train should be as short as possible, so that it can be put into short sidings or clear of fouling points when at an accident. A compact train consisting of a six-wheel van at each end, with a steam crane and its safety wagon in the middle, can be made up with an overall length of under 125 feet, exclusive of the engine. All such trains should have a van at each end as it saves much delay in not having to reverse the brake van.

The brake vans should be fitted with vacuum brake cylinders as well as hand brake, and the crane and safety wagon with through pipes and a hand brake; a very useful fitting on the crane is a valve for applying the vacuum brake with an application handle at the corner of the frame, so that when setting the crane a man on the ballast can 
instantly apply the brake instead of having to signal to someone on the engine. I consider a satisfactory crane equipment for a railway of ordinary mileage would be four steam cranes, one being 35 tons and the other three 25 tons lifting capacity, the larger being stationed at an important centre.

The cost of these cranes would be heavy, but in addition to accident work they can be used for changing wheels or lifting for hot boxes at the sheds, or again for relaying points and crossings for the Permanent Way Department.

As regards hydraulic lifting and traversing jacks, it is more convenient to have them of 20 tons than of 30 tons capacity, the latter being a heary article to move about when stumbling over sleepers and rails on a dark night.

The most useful lights for night work are, I consider, acetylene lamps, one or two in a train being of $I, 000$ candle power, with others of lesser candle power, and for inspection the hand pattern. The old fashioned duck lamps are horrible things with which to work, and a good general light from a high power lamp is a great boon.

Another appliance is of considerable service in dealing with intermediate drawbars between engine and tender when twisted, and also dressing off bent steel framings to clear the gauge; I refer to an oxy-acetylene cutting plant. In oases where a tender is lying over at an angle to the engine it is generally an extremely difficult and in some cases impossible thing to remove the pin without first straightening the tender, which may not be possible for some time; much time is then saved by using the plant mentioned.

So far I have dealt only with material matters, but in conclusion I will mention the other side in the work of a Running Department, and that is the staff or human side. Questions of discipline, responsibility for accidents and irregularities take up a large portion of a running superintendent's time. Just as it is important that the relations between the heads of departments should be good, so it is that there should be good relations between the staff of a department and their head. In conclusion, I would impress on those of the younger members and graduates of this Institution the importance of studying the management of men as being well worth their attention-tactfulness often overcoming difficult situations.

A great deal can be learned when working in the workshops during the first years of their training, which will always be of use to them afterwards when they have charge of men. 